\title{
Monk business: An example of the dynamics of organizations
}

\author{
Luis C. Corchón \\ ${ }^{1}$ Department of Economics, Universidad Carlos III, c/Madrid 126, Getafe, \\ 28903 Madrid, Spain (e mail: lcorchon@eco.uc3m.es)
}

Received: 26 April 2001/Accepted: 29 December 2003

\begin{abstract}
In this paper we present a dynamic model of an organization. It is shown that the quality of the members of the organization may change cyclically and that even if the organization promotes excellence, the organi zation may end up populated mostly by mediocre agents.
\end{abstract}

\section{Introduction}

The last two decades have seen a growing interest in the theory of organi zation. Using the tools of game theory and contract theory, economists have begun to understand some basic features like incentive schemes, organiza tional forms or property rights inside the firm. But very little attention has been paid to the interplay between the internal structure of the organization and the environment in a dynamic set up.

In this paper, we focus on the fact that organizations must offer selective prizes say, promotions in order to attract people inside the organization. Unfortunately these prizes attract all kind of agents. Suppose that agents are free to enter but the organization has a technology for distinguishing (imperfectly) "talented" from "untalented" agents. One should expect that if the technology is able to select talented agents with an arbitrarily large probabilily, this should stop untalented agents from entering into the orga nization. But this is not necessarily the case: In a dynamic setting, the organization may be subject to cycles. And if the organization is well

I am grateful to Carmen Beviá, Clara Eugenia García, Iñigo Iturbe Ormaetxe, Ignacio Ortuño Ortín, Piero Gottardi, an anonymous referee and the participants in a seminar in the Institute for Advanced Studies, Vienna for very helpful comments and to CICYT for financial support under grant BEC2002 02194. 
managed by a talented agent, this provides an extra incentive for untalented agents to enter even if they know that they will get no prize.

In this paper we propose a simple model characterized by the following features:

1. The organization is subject to entry and exit. We model this by an overlapping generation model in which agents are free to enter and live for two periods.

2. Agents are heterogeneous. We assume that they belong to two categories: Talented or untalented.

3. The organization is hierarchic. In the first period, agents perform some routine task for which all agents are equally capable. At the beginning of the second period, one of them is chosen to be the boss. The other agents have the choice of leaving the organization if they wish to do so.

4. There are externalities inside the organization. If the boss is talented all other agents are better off than in a situation in which the boss is untalented.

For the sake of tractability we ignore important features of organizations such as competition among organizations, loyalties, durable capital, complexity and incentives. ${ }^{1}$ In this framework, we introduce two additional simplifications in order to keep the model tractable: a) The rules under which the boss is chosen are exogenous. b) A talented agent does not create externalities if he is not the boss and his productivity is the same as the productivity of an untalented agent in the routine task.

Our model may be suited for studying some aspects of organizations such as non profit organizations, a political party such as the communist party in the extinct U.S.S.R. or the fascist party in Mussolini's Italy, or a department in an university. ${ }^{2}$ In order to couch the previous items in our framework it is better to think of a small branch of the organization, such as a small town branch of the communist party, and not, say, the Politburo.

Our leading example is that of an abbey in medieval Europe. Early on in their lives, farmers decide to enter into the abbey or to remain peasants. If a young peasant decides to become a monk he will spend the next period (say 25 years) copying manuscripts and farming according to the direction of the current abbot. In our model, when entering the abbey, young peasants do not know who the abbot will be, but they know the probability of the abbot being

${ }^{1}$ See Radner (1991) for an overview of incentives in a dynamic setting and Sjostrom and Weitzman (1996) for a model where competition among organizations helps to maintain quality at a efficient level.

${ }^{2}$ In the latter case, free entry is motivated by the fact that, given the large demand for higher education, restrictions to become a faculty member were not important in many parts of Europe. 
talented (or untalented). ${ }^{3}$ This probability is exogenously given and it might be different for talented and untalented agents reflecting the degree of adverse selection inside the organization. At the beginning of the second period, there is a lottery involving all peasants who entered in the previous period and a new abbot is appointed (for the next 25 years). We decide to model the election as a lottery to capture the uncertainties associated with the election of the new abbot. Agents who participated in the election other than the abbot either leave or spend this new period ( 25 more years) in the abbey.

Our equilibrium concept is very simple. Agents are expected utility maximizers and know all the relevant parameters of the model. The number of talented (resp. untalented) monks entering the abbey is such that the undiscounted expected utility of being a monk equals reservation utility. If the latter is larger than the undiscounted expected utility that a talented (resp. untalented) farmer can obtain by entering the abbey, no talented (resp. untalented) farmer enters monastic life.

In Section 3, we focus on steady states (SS), where each cohort has the same number of talented and untalented monks as the previous one. We show that under reasonable assumptions, there is always a unique SS. The SS can be of three different classes: A SS with untalented monks only (a SSU), a SS with talented monks only (a SST) and a SS with both talented and untalented monks (a SSM). Next we study the dependence of SS on the two main parameters of the model, namely the relative probability that the abbot is talented (denoted by $k$ ) and the amount of positive externality imposed by a talented abbot (denoted by $\delta$ ). When $k$ is low, talented people are not attracted into the organization and only SSU exist. For intermediate values of $k$ only SSM exists. If $\delta$ is relatively low, for large $k$ only SST exists. But if $\delta$ is large, there is no SST, no matter how high $k$ is and the only SS is a SSM. The explanation of this fact is that for $k$ large the abbot is almost surely talented. Untalented monks receive a large externality from a talented abbot and they keep entering into the abbey even when their chances to become abbot are almost zero. We call this the umbrella effect.

In Sect. 4 , we analyze the dynamic system. If $k$ and $\delta$ are such that only SSU (resp. SST) exists the SSU (SST) is globally stable. For values of $k$ and $\delta$ for which a SSM exists, there are several possibilities. The SSM can be globally stable, locally unstable or it might, under exceptional circumstances, produce a cycle with two values: a cohort with a relatively large number of talented monks is followed by a cohort with a relatively large number of untalented monks and this cohort is followed by a cohort identical to the first one, etc.

\footnotetext{
${ }^{3}$ An alternative assumption is that young peasants know who will be the abbot for the next period. But given that our periods are interpreted as consisting of a large number of years, we think that the formalization chosen here better captures the uncertainties associated with the future performance of the current abbot.
} 
The paper ends with a section gathering our conclusions and suggesting further possibilities of research in this framework.

\section{The model}

There is a large population of potential monks composed of two kind of agents, talented and untalented. They live for two periods. At the beginning of the first period they might join the abbey. The number of talented (resp. untalented) agents entering monastic life in period $t$ is denoted by $n_{T}^{t}$ (resp. $\left.n_{U}^{t}\right)$. In order to simplify the analysis, we will disregard integer problems and so we will handle the number of talented and untalented monks as a continuous variable. The abbot for the period $t+1$ is chosen among all members of the cohort that entered at $t$. We model the election as a lottery. The probability that a particular talented (resp. untalented) monk is chosen to be the abbot in period $t+1$ is

$$
\frac{k}{k n_{T}^{t}+n_{U}^{t}},\left(\text { resp. } \frac{1}{k n_{T}^{t}+n_{U}^{t}}\right) \text {. }
$$

Thus, the probability that the abbot is talented (resp. untalented) is

$$
\frac{k n_{T}^{t}}{k n_{T}^{t}+n_{U}^{t}},\left(\text { resp. } \frac{n_{U}^{t}}{k n_{T}^{t}+n_{U}^{t}}\right) \text {. }
$$

The parameter $k$ measures the taste for talent inside the organization. If $0<k<1$ any talented farmer has lower chances of becoming an abbot than any untalented farmer. If $k=1$, all agents have equal chances (this might be interpreted as pure adverse selection). Finally when $k \rightarrow \infty$ the probability that the chosen abbot is talented approaches one. We remark that the election of the abbot might be governed by deterministic rules. In this case, $k$ reflects the uncertainties associated with the process of election (coalitions, loyalties, etc.) as they are perceived by entrants. We will assume that $k$ is exogenously given, i.e., it is set by the Vatican or by customary uses inside the monastery.

In the first period, monks perform a routine task for which all of them (talented or untalented) are equally capable. Let $w$ be the utility of a monk in his first period if the abbot is untalented and $\delta w$ his utility if the abbot is talented. Since a talented abbot will provide better design and organization of the basic tasks performed by the monks we assume that $\delta>1$. Let $V$ be the utility of the abbot. ${ }^{4}$ Finally, let $u_{T}$ (resp. $u_{U}$ ) be the lifetime reservation utility of a talented (resp. untalented) farmer who does not join the abbey.

After the election the monks of the older generation who lost the election can remain in the abbey, or may leave. We do not model this choice since it is

\footnotetext{
4 To simplify notation, we assume that the utility of the abbot is independent of his type. It can be shown that all our conclusions hold if the utility of the abbot depends on his type.
} 
immaterial for the model. Let $w_{T}^{\prime}$ (resp. $w_{U}^{\prime}$ ) be the expected utility in the second period for a talented (resp. untalented) monk other than the abbot if the abbot is untalented and $w_{T}^{\prime \prime}$ (resp. $w_{U}^{\prime \prime}$ ) be the expected utility of a talented (resp. untalented) monk other than the abbot if the abbot is talented. We assume that $w_{T}^{\prime \prime}>w_{T}^{\prime}$ and $w_{U}^{\prime \prime}>w_{U}^{\prime}$.

Let us now concentrate on the decision problem of a potential monk. In the first period he can obtain $w$ with probability

$$
\frac{n_{U}^{t}{ }^{1}}{k n_{T}^{t}{ }^{1}+n_{U}^{t}{ }^{1}}
$$

and $\delta w$ with probability

$$
\frac{k n_{T}^{t}{ }^{1}}{k n_{T}^{t}{ }^{1}+n_{U}^{t}{ }^{1}} \text {. }
$$

Thus his expected utility in the first period is

$$
\frac{w\left(\delta k n_{T}^{t}{ }^{1}+n_{U}^{t}{ }^{1}\right)}{k n_{T}^{t}{ }^{1}+n_{U}^{t}{ }^{1}} .
$$

We remark that expected utility in the first period is independent of the type. However in the second period the expected utility of talented and untalented monks are different. Let us consider the case of a talented agent first. In the second period there are three possible outcomes. An untalented monk may be chosen to be the abbot with probability

$$
\frac{n_{U}^{t}}{k n_{T}^{t}+n_{U}^{t}}
$$

and, in this case, he would get $w_{T}^{\prime}$. He can be the abbot with probability

$$
\frac{k}{k n_{T}^{t}+n_{U}^{t}}
$$

so he would get $V$. Finally another talented monk may be the abbot. Since all the probabilities must add up to one this event occurs with probability

$$
1-\frac{n_{U}^{t}+k}{k n_{T}^{t}+n_{U}^{t}}=\frac{k\left(n_{T}^{t}-1\right)}{k n_{T}^{t}+n_{U}^{t}} .
$$

In this case he gets $w_{T}^{\prime \prime}$. Adding all the terms, the undiscounted lifetime expected utility $\left(E_{T}\right)$ of a talented monk is ${ }^{5}$

$$
E_{T} \equiv \frac{w\left(\delta k n_{T}^{t}{ }^{1}+n_{U}^{t}{ }^{1}\right)}{k n_{T}^{t}{ }^{1}+n_{U}^{t}{ }^{1}}+\frac{k V+w_{T}^{\prime} n_{U}^{t}+k w_{T}^{\prime \prime}\left(n_{T}^{t}-1\right)}{k n_{T}^{t}+n_{U}^{t}} .
$$

A similar argument for a typical untalented monk shows that his expected lifetime utility $\left(E_{U}\right)$ is

${ }^{5}$ It can be shown that all our main conclusions hold if utility is discounted. 


$$
E_{U} \equiv \frac{w\left(\delta k n_{T}^{t}{ }^{1}+n_{U}^{t}{ }^{1}\right)}{k n_{T}^{t}{ }^{1}+n_{U}^{t}{ }^{1}}+\frac{V+k w_{U}^{\prime \prime} n_{T}^{t}+w_{U}^{\prime}\left(n_{U}^{t}-1\right)}{k n_{T}^{t}+n_{U}^{t}} .
$$

Let the right hand side of Eqs. (1) and (2) be written as

$$
\left.E_{T}\left(n_{T}^{t}{ }^{1}, n_{U}^{t}{ }^{1}, n_{U}^{t}, n_{T}^{t}\right), E_{U}\left(n_{T}^{t}{ }^{1}, n_{U}^{t}{ }^{1}, n_{U}^{t}, n_{T}^{t}\right)\right) .
$$

Definition 1. A Dynamic Equilibrium (DE) given an initial condition $\left(n_{U}^{0}, n_{T}^{0}\right)$ is a sequence $\left(n_{U}^{t}, n_{T}^{t}\right)_{t=1, \ldots, \infty}$ fulfilling the following two conditions:

$E_{T}\left(n_{T}^{t}{ }^{1}, n_{U}^{t}{ }^{1}, n_{U}^{t}, n_{T}^{t}\right) \leq u_{T}$ and if strict inequality holds then $n_{T}^{t}=0$,

$E_{U}\left(n_{T}^{t}{ }^{1}, n_{U}^{t}{ }^{1}, n_{U}^{t}, n_{T}^{t}\right) \leq u_{U}$ and if strict inequality holds then $n_{U}^{t}=0$.

Thus, a $D E$ requires for each cohort that entry into the abbey reaps any possible utility gain that agents can obtain by entering into monastic life. ${ }^{6}$

A first glimpse into the properties of a $D E$ can be obtained by studying the particular case in which in each period, the entering cohort is identical to the previous one. This motivates the following definition:

Definition 2. A Steady State (SS) is a pair $\left(n_{U}^{*}, n_{T}^{*}\right)$ such that:

$E_{T}\left(n_{T}^{*}, n_{U}^{*}, n_{U}^{*}, n_{T}^{*}\right) \leq u_{T}$ and if strict inequality holds then $n_{T}^{*}=0$,

$$
E_{U}\left(n_{T}^{t *}, n_{U}^{*}, n_{U}^{*}, n_{T}^{*}\right) \leq u_{U} \text { and if strict inequality holds then } n_{U}^{*}=0 .
$$

Taking into account (1) and (2), Eqs. (5) and (6) can be written as:

$$
\begin{aligned}
& n_{U}^{*}\left(w+w_{T}^{\prime}-u_{T}\right)+k\left(V-w_{T}^{\prime \prime}\right) \leq k n_{T}^{*}\left(u_{T}-w \delta-w_{T}^{\prime \prime}\right), \\
& n_{U}^{*}\left(w+w_{U}^{\prime}-u_{U}\right)+V-w_{U}^{\prime} \leq k n_{T}^{*}\left(u_{U}-w \delta-w_{U}^{\prime \prime}\right) .
\end{aligned}
$$

with inequality strict if the corresponding number of monks is zero.

\section{Steady states}

In order to study the existence of a steady states, some assumptions are needed.

\footnotetext{
${ }^{6}$ A more stringent definition of a dynamic equilibrium would require that further entry from either type yields an expected utility for this type less than the reservation utility.
} 
Assumption 1. $V>\max \left(w_{T}^{\prime \prime}, w_{U}^{\prime \prime}, \delta w\right)$.

This assumption says that the utility of the abbot is greater than any other utility that individuals can get in any period (in other words, "It's good to be the king" after the famous line by Mel Brooks, History of the World, Part One 1981). Thus, the chosen abbot has incentives to remain in the abbey.

Notice that if the reservation utility of a type is low enough, an infinite number of farmers will join the monastery. Thus, the existence of a SS requires that the reservation utility of both types is large enough. In fact we require the following:

Assumption 2. $u_{T}>\delta w+w_{T}^{\prime \prime}$ and $u_{U}>w+w_{U}^{\prime}$.

This assumption says that a farmer can get outside the monastery at least as much he can get working in the routine task inside the monastery when directed by an abbot of his own type. The interpretation is that a peasant can perform a similar task inside and outside the monastery but a non monastic life provides some extra utility. Two consequences of this assumption are that for a talented farmer to be attracted to monastic life he must have some chance of becoming abbot and that for an untalented farmer to become attracted to monastic life he must have either the chance to become an abbot or to have his work being directed by a talented abbot.

Finally we assume the following:

Assumption 3.

$$
\frac{u_{T}}{u_{U}}>\frac{w(\delta-1)+w_{T}^{\prime \prime}-w_{T}^{\prime}}{w(\delta-1)+w_{U}^{\prime \prime}-w_{U}^{\prime}} .
$$

The numerator (resp. denominator) of the right hand side of the above condition is the marginal effect of the talent of the abbot on payoffs obtained by a talented (resp. untalented) farmer. Thus, the right hand side of the inequality is a relative measure of the impact of a talented abbot on payoffs. Assumption 3 says that the ratio of lifetime reservation utility of talented over untalented farmers is greater than the ratio of gains due to the talent of the abbot. In other words, one's talent is more important to success than other people's talent. In the special case in which payoffs in the second period do not depend on types $w_{T}^{\prime \prime}=w_{U}^{\prime \prime}, w_{T}^{\prime}=w_{U}^{\prime}$ and this assumption reads $u_{T}>u_{U}$.

In the rest of the paper we will assume that Assumptions 1, 2 and 3 hold.

Now we are prepared to tackle the issue of existence of SS. It is clear that there are three possible SS. A SS in which only untalented monks join the monastery (SSU), a mixed SS in which both talented and untalented monks join the monastery (SSM) and a SS in which only talented monks join the monastery (SST).

Let us first concentrate on the SSU. From (7) and (8) it follows that

$$
n_{T}^{*}=0, n_{U}^{*}=\frac{V-w_{U}^{\prime}}{u_{U}-w-w_{U}^{\prime}} \text { and for } E_{T}^{*}<u_{T}, k<\frac{\left(V-w_{U}^{\prime}\right)\left(u_{T}-w-w_{T}^{\prime}\right)}{\left(V-w_{U}^{\prime \prime}\right)\left(u_{U}-w-w_{U}^{\prime}\right)} \text {. }
$$


Assumptions 1 and 2 imply that expression in the right hand side of the inequality is positive. Thus, a SSU exists when $k$ small enough.

Let us now compute a SSM. From (7) and (8) it follows that

$$
\begin{aligned}
& n_{T}^{*}=\frac{k\left(V-w_{T}^{\prime \prime}\right)\left(u_{U}-w-w_{U}^{\prime}\right)-\left(V-w_{U}^{\prime}\right)\left(u_{T}-w-w_{T}^{\prime}\right)}{k\left[\left(u_{T}-\delta w-w_{T}^{\prime \prime}\right)\left(u_{U}-w-w_{U}^{\prime}\right)-\left(u_{T}-w_{T}^{\prime}-w\right)\left(u_{U}-\delta w-w_{U}^{\prime \prime}\right)\right]} \\
& n_{U}^{*}=\frac{\left(V-w_{U}^{\prime}\right)\left(u_{T}-\delta w-w_{T}^{\prime \prime}\right)-k\left(V-w_{T}^{\prime \prime}\right)\left(u_{U}-\delta w-w_{U}^{\prime \prime}\right)}{\left(u_{T}-\delta w-w_{T}^{\prime \prime}\right)\left(u_{U}-w-w_{U}^{\prime}\right)-\left(u_{T}-w_{T}^{\prime}-w\right)\left(u_{U}-\delta w-w_{U}^{\prime \prime}\right)} .
\end{aligned}
$$

A little bit of algebra shows that Assumption 3 implies that the denominator of the expressions defining $n_{T}$ and $n_{U}$ is positive. Thus, the non negativity conditions for the numerators boil down to

$$
\frac{\left(V-w_{U}^{\prime}\right)\left(u_{T}-w-w_{T}^{\prime}\right)}{\left(V-w_{U}^{\prime \prime}\right)\left(u_{U}-w-w_{U}^{\prime}\right)} \leq k \leq \frac{\left(V-w_{U}^{\prime}\right)\left(u_{T}-\delta w-w_{T}^{\prime \prime}\right)}{\left(V-w_{T}^{\prime \prime}\right)\left(u_{U}-\delta w-w_{U}^{\prime \prime}\right)},
$$

where the second inequality only needs to hold when $u_{U}>\delta w+w_{U}^{\prime \prime}$. Otherwise the numerator of the expression of $n_{U}^{*}$ and, consequently, $n_{U}^{*}$ are always positive.

Finally, in a SST we have that

$$
n_{T}^{*}=\frac{V-w_{T}^{\prime \prime}}{u_{T}-\delta w-w_{T}^{\prime \prime}}, n_{U}^{*}=0 \text { and for } E_{U}^{*}<u_{U}, k>\frac{\left(V-w_{U}^{\prime}\right)\left(u_{T}-\delta w-w_{T}^{\prime \prime}\right)}{\left(V-w_{T}^{\prime \prime}\right)\left(u_{U}-\delta w-w_{U}^{\prime \prime}\right)} .
$$

The previous arguments are summarized in the following result:

Theorem 1. For every $k$ there is a unique SS. For values of $k$ low enough there only exists SSU. For intermediate values of $k$ there only exists SSM. For high values of $k$ a SST exists only if $u_{U}>\delta w+w_{U}^{\prime \prime}$. If $u_{U} \leq \delta w+w_{U}^{\prime \prime}$ only $S S M$ exists. ${ }^{7}$

The interpretation of Theorem 1 is that if the value of $k$ is low, only SSU exists since talented farmers have little chance of becoming promoted and thus they have no incentive to join the monastery. For intermediate values of $k$ both talented and untalented farmers are attracted to the monastery. For large values of $k$ there are two cases: If $\delta$ is relatively low or the reservation value of untalented farmers is relatively high (i.e. if $u_{U}>\delta w+w_{U}^{\prime \prime}$ ) they do not enter into the monastery because their chances to become abbot, measured by

$$
\frac{n_{U}^{*}}{k n_{T}^{*}+n_{U}^{*}}
$$

are small. In fact, this probability decreases with $k$ and tends to zero when $k$ tends to infinity. But if $\delta$ is relatively high or the reservation value of untalented farmers is relatively low (i.e. $u_{U} \leq \delta w+w_{U}^{\prime \prime}$ ), they enter the monastery

${ }^{7}$ If the number of monks is bound to be an integer, several SS may exist for a given $k$. 
in large numbers, because even though their chances to become an abbot are small, the chances that they will be directed by a talented person are high and this provides extra utility with respect to the utility they would get as farmers. In this case, the Vatican can not achieve abbeys populated by talented monks only by setting $k$ arbitrarily large. On the contrary, it is easily computed that

$$
\frac{n_{U}^{*}}{n_{T}^{*}} \rightarrow \infty \text { when } k \rightarrow \infty \text {. }
$$

Thus an increase in the probability that a talented person becomes the abbot increases the number of untalented monks relative to the number of talented monks. We will call this the umbrella effect because it reflects the role of the leader as an umbrella of the mediocre.

\section{Dynamic paths}

In this section we provide an analysis of the dynamic equilibrium. Due to the complexity of the trajectories we will focus on the special case in which expected utilities in the second period do not depend on the type of the monk. Thus, $w_{T}^{\prime}=w_{U}^{\prime} \equiv w^{\prime}$, say and $w_{U}^{\prime \prime}=w_{T}^{\prime \prime} \equiv w^{\prime \prime}\left(>w^{\prime}\right)$. An extreme form of this assumption is when monks can not leave the monastery and get $w$ (resp. $\delta w$ ) if the abbot is untalented (talented). In this case $w^{\prime}=w$ and $w^{\prime \prime}=\delta w$.

Assumptions 1-2-3 read now $V>\max \left(\delta w, w^{\prime \prime}\right), \quad u_{T}>w \delta+w^{\prime \prime}$, $u_{U}>w+w^{\prime}$, and $u_{T}>u_{U}$. Thus, the assumption made above says that talent is payoff relevant only when an agent is young. In order to simplify notation let

$$
a^{t} \equiv \frac{w\left(n_{U}^{t}+k \delta n_{T}^{t}\right)}{n_{U}^{t}+k n_{T}^{t}}
$$

It is easily seen that $\delta w \geq a^{t} \geq w$. With this notation in hand and for the special case considered in this section, expected utility for talented and untalented monks (Eqs. (1) and (2)) can be written as follows:

$$
\begin{aligned}
& E_{T} \equiv a^{t}{ }^{1}+\frac{k V+w^{\prime} n_{U}^{t}+k w^{\prime \prime}\left(n_{T}^{t}-1\right)}{k n_{T}^{t}+n_{U}^{t}} . \\
& E_{U} \equiv a^{t}{ }^{1}+\frac{V+k w^{\prime \prime} n_{T}^{t}+w^{\prime}\left(n_{U}^{t}-1\right)}{k n_{T}^{t}+n_{U}^{t}} .
\end{aligned}
$$

Let us consider first the case in which $k$ is such that there is SSU only, i.e.

$$
k<\frac{\left(V-w^{\prime}\right)\left(u_{T}-w-w^{\prime}\right)}{\left(V-w^{\prime \prime}\right)\left(u_{U}-w-w^{\prime}\right)} .
$$

Suppose that in period $t$ both types of monks enter the monastery. Then,

$$
n_{T}^{t}=\frac{k\left(V-w^{\prime \prime}\right)\left(u_{U}-w^{\prime}-a^{t}{ }^{1}\right)-\left(V-w^{\prime}\right)\left(u_{T}-w^{\prime}-a^{t}{ }^{1}\right)}{k\left(w^{\prime \prime}-w^{\prime}\right)\left(u_{T}-u_{U}\right)} .
$$


Since $n_{T}^{t} \geq 0, u_{U}>w^{\prime}+a^{t}{ }^{1}$. Thus,

$$
k \geq \frac{\left(V-w^{\prime}\right)\left(u_{T}-w^{\prime}-a^{t}{ }^{1}\right)}{\left(V-w^{\prime \prime}\right)\left(u_{U}-w^{\prime}-a^{t}{ }^{1}\right)} .
$$

Combining both inequalities involving $k$ we get $u_{T}\left(w-a^{t}{ }^{1}\right)>u_{U}\left(w-a^{t}{ }^{1}\right)$ which is impossible. Suppose now that only talented farmers enter. This implies that

$$
\frac{V-w^{\prime}+k w^{\prime \prime} n_{T}^{t}}{k n_{T}^{t}}+a^{t}{ }^{1}<u_{U} \text { and } n_{T}^{t}=\frac{V-w^{\prime \prime}}{u_{T}-w^{\prime}-a^{t}} .
$$

These equations imply that

$$
k \geq \frac{\left(V-w^{\prime}\right)\left(u_{T}-w^{\prime \prime}-a^{t}{ }^{1}\right)}{\left(V-w^{\prime \prime}\right)\left(u_{U}-w^{\prime \prime}-a^{t}{ }^{1}\right)} .
$$

Combining both inequalities involving $k$ we get $\left.u_{U}\left(a^{t} 1-w-w^{\prime}+w^{\prime \prime}\right)\right)>$ $u_{T}\left(a^{t}{ }^{1}-w-w^{\prime}+w^{\prime \prime}\right)$ which implies $a^{t}{ }^{1}-w<w^{\prime}-w^{\prime \prime}$ which is impossible because the term on the left hand side is non negative and the term on the right hand side is negative. So there can not be a period in which only talented farmers enter.

The last possibility is that only untalented farmers enter at $t$. In this case Eqs. (7) and (8) imply that

$$
n_{U}^{t}=\frac{V-w^{\prime}}{u_{U}-w^{\prime}-a^{t} 1} \text { and } k<\frac{\left(V-w^{\prime}\right)\left(u_{T}-w^{\prime}-a^{t}{ }^{1}\right)}{\left(V-w^{\prime \prime}\right)\left(u_{U}-w^{\prime}-a^{t}{ }^{1}\right)} .
$$

It is easy to show (by contradiction) that the last inequality is implied by the bound on $k$ in a SSU. Finally notice that for $t>1 a^{t}=w$ and the equations above coincide with those defining a SSU. Thus, we have proved the following:

Theorem 2. Suppose that only SSU exists. Then, there is a unique DE which from Period 2 on coincides with the SSU.

A similar argument proves the following analogous result:

Theorem 3. Suppose that only SST exists. Then, there is a unique DE which from Period 2 on coincides with the SST.

Theorems 2 and 3 say that both SSU and SST are globally stable.

Let us now concentrate on the case in which a SSM exists. Let us look for a DE in which both types enter. In this case, Eqs. (3), (4), (9) and (10) imply

$$
n_{T}^{t}=\frac{k\left(V-w^{\prime \prime}\right)\left(u_{U}-w^{\prime}-a^{t}{ }^{1}\right)-\left(V-w^{\prime}\right)\left(u_{T}-w^{\prime}-a^{t}{ }^{1}\right)}{k\left(w^{\prime \prime}-w^{\prime}\right)\left(u_{T}-u_{U}\right)} \equiv f_{T}\left(a^{t}{ }^{1}\right),
$$




$$
n_{U}^{t}=\frac{k\left(V-w^{\prime \prime}\right)\left(w^{\prime \prime}+a^{t}{ }^{1}-u_{U}\right)-\left(V-w^{\prime}\right)\left(w^{\prime \prime}+a^{t}{ }^{1}-u_{T}\right)}{\left(w^{z \prime \prime}-w^{\prime}\right)\left(u_{T}-u_{U}\right)} \equiv f_{U}\left(a^{t}{ }^{1}\right) .
$$

The corresponding non-negativity constraints are:

$$
\begin{aligned}
& R u_{U}-u_{T}+w^{\prime}(1-R) \geq a^{t}{ }^{1}(R-1) \geq w^{\prime \prime}(1-R)+R u_{U}-u_{T} . \\
& \text { where } R \equiv \frac{k\left(V-w^{\prime \prime}\right)}{\left(V-w^{\prime}\right)} .
\end{aligned}
$$

Notice that the bounds for $k$ in a SSM and $w^{\prime \prime}>w^{\prime}$ imply that $R>1$ and thus (13) can be written as

$$
\frac{R u_{U}-u_{T}}{R-1}-w^{\prime} \geq a^{t} 1 \geq \frac{R u_{U}-u_{T}}{R-1}-w^{\prime \prime} .
$$

Equation (14) is necessary and sufficient for the existence of a DE in which both types enter. Moreover, (14) implies that the inequalities defining a SSM hold since

$$
\begin{aligned}
& R u_{U}-u_{T}-w^{\prime}(R-1) \geq a^{t}{ }^{1}(R-1) \geq w(R-1), \Longrightarrow R \geq \frac{u_{T}-w-w^{\prime}}{u_{U}-w-w^{\prime}} \\
& R u_{U}-u_{T}+w^{\prime \prime}(1-R) \leq a^{t}{ }^{1}(R-1) \leq(R-1) w \delta \Longrightarrow R \leq \frac{u_{T}-\delta w-w^{\prime \prime}}{u_{U}-\delta w-w^{\prime \prime}} .
\end{aligned}
$$

It is easy to check that the inequalities on the right hand side of (15) and (16) are identical to those defining a SSM.

Suppose that the value of $a^{t}{ }^{1}$ is such that (14) holds. We plug equations (11) and (12) in the definition of $a^{t}$ and get an equation relating $a^{t}$ and $a^{t}$, denoted by $a^{t}=f\left(\begin{array}{ll}a^{t} & 1\end{array}\right)$. Notice that from (11) and (12) it follows that

$$
n_{U}^{t}+k n_{T}^{t}=\frac{k\left(V-w^{\prime \prime}\right)-\left(V-w^{\prime}\right)}{u_{T}-u_{U}},
$$

i.e. $n_{U}^{t}+k n_{T}^{t}$ is independent of $a$. Thus,

$$
\frac{d a^{t}}{d a^{t} 1}=\frac{w}{n_{U}^{t}+k n_{T}^{t}}\left(\frac{d f_{U}}{d a^{t} 1}+\delta k \frac{d f_{T}}{d a^{t} 1}\right)=\frac{w(1-\delta)}{w^{\prime \prime}-w^{\prime}}<0 .
$$

We have three cases. If the impact of the talent of the abbot on the utility of other monks is larger in the second period than in the first period, $w^{\prime \prime}-w^{\prime}>w(\delta-1)$. Thus, $\frac{d a^{t}}{d a^{t} 1}>-1$, and the system is stable. If the reverse inequality holds, $\frac{d a^{t}}{d a^{t}}<-1$ and the system is unstable. Finally, in the exceptional case in which the impact of the talent of the abbot on the utility of other monks is identical in both periods, $w^{\prime \prime}-w^{\prime}=w(\delta-1), \frac{\partial a^{t}}{\partial a^{t}}=-1 .^{8}$ In

${ }^{8}$ This case arises if, for instance, monks can not leave the monastery and get $w$ (resp. $\delta w)$ if the abbot is untalented (talented). 
this case, the $D E$ is cyclical. We start with a value of $a^{0}$ which implies certain value of $a^{1}=f\left(a^{0}\right)$. In period 2, we have that $a^{2}=a^{0}$, in period $3, a^{3}=a^{1}$, so on and so forth. Therefore, $n_{T}^{t}$ and $n_{U}^{t}$ take only two values. ${ }^{9}$ This case, though, depends on a very special configuration of parameters.

In order to tackle the case where (14) does not hold, let us assume that the bounds defining an SSM hold strictly. Suppose that the first inequality in (14) is violated in period $t$, i.e.

$$
\frac{R u_{U}-u_{T}}{R-1}-w^{\prime}<a^{t} \quad 1 .
$$

This implies that $n_{T}^{t}=0$ and, thus, $a^{t}=w$. But in period $t+1$, the first inequality in (14) must hold, i.e.

$$
\frac{R u_{U}-u_{T}}{R-1}-w^{\prime} \geq a^{t}=w .
$$

because if not, $R\left(u_{U}-w-w^{\prime}\right)<u_{T}-w-w^{\prime}$ and this would violate (15). Thus, in $t+1$, the first inequality of (14) holds.

Suppose that the second inequality of (14) is not fulfilled at $t+1$, i.e.

$$
\frac{R u_{U}-u_{T}}{R-1}-w^{\prime \prime}>a^{t}=w \text {. }
$$

But then, $n_{U}^{t+1}=0$, so $a^{t+1}=\delta w$. Thus, in period $t+2$ this inequality holds because if not we would have

$$
\frac{R u_{U}-u_{T}}{R-1}-w^{\prime \prime}>a^{t+1}=w \delta \Longrightarrow u_{T}-\delta w-w^{\prime \prime}<R\left(u_{U}-\delta w-w^{\prime \prime}\right),
$$

contradicting (16). The first inequality in Eq. (14) is also satisfied in $t+2$ because if it were not

$$
\frac{R u_{U}-u_{T}}{R-1}-w^{\prime}<a^{t+1}=\delta w<\delta w-w^{\prime \prime} \Longrightarrow \frac{R u_{U}-u_{T}}{R-1}<\delta w-w^{\prime \prime},
$$

and this contradicts Eq. (16). Thus, after two periods $a^{t+1}$ enters in the interval defined by (14). A similar analysis can be done to deal with the case where the other inequality in (13) is violated in period $t$, i.e.

$$
\frac{R u_{U}-u_{T}}{R-1}-\delta w>a^{t} 1
$$

All these findings are summarized in the following:

Theorem 4. Suppose that only SSM exists. If $w^{\prime \prime}-w^{\prime}>w(\delta-1)$ the dynamic system achieves the SSM in, at most, three periods. If $w^{\prime \prime}-w^{\prime}<w(\delta-1)$ the $S S M$ is locally unstable. If $w^{\prime \prime}-w^{\prime}=w(\delta-1)$ from Period 3 on, the DE exhibits permanent cyclic behavior with two values only.

${ }^{9}$ It can be shown that the average of these values is the SSM. 


\section{Conclusions}

This paper studies dynamic organizations using well-known concepts: Overlapping generations (introduced by Samuelson and used extensively in monetary economics), externalities (used from Pigou on to analyze market failure), hierarchies (that play an important role in the writings of Williams) and types (from Vickrey and Harsanyi, an idea that pervades the whole game theory). What we found in this paper is that assumptions on how talent affects payoffs pervade the analysis and drive the main results.

Our analysis has produced two main conclusions.

On the one hand, organizations having a homogeneous population in the steady state are stable. Organizations in which the population is not homogeneous in the steady state may be stable, unstable or they might even cycle.

On the other hand, an organization with high standards of promotion can be mostly populated by untalented persons. Why? Because untalented people may live very well under the direction of a talented person, i.e., the umbrella effect. This effect provides an explanation to the casual observation that, sometimes, intelligent leaders are surrounded by not-so-intelligent people. The usual explanation of this fact is that, some intelligent people do not like to be surrounded by potential challengers. Without denying that this may be the case in some instances, our analysis provides an alternative answer: Intelligent bosses provide an umbrella under which the mediocre prosper. In other words, if untalented agents profit more in relative terms than the talented ones from having a good boss, untalented agents will enter in larger numbers than talented agents. Of course, in real organizations, there might be forces operating in the opposite direction, for instance, the entry of untalented agents may be restricted by entry examinations. However our point is that there is a tendency for the relatively untalented to enter in large numbers, no matter how high the standard of promotion is. An unpleasant consequence of this is that the outcome of a policy of excellence may be not excellence but mediocrity.

The model can be extended in several directions. We might introduce several bosses. Also it would be interesting to consider that $k$ is endogenous. ${ }^{10}$ For instance, $k$ might depend on the current number of talented and untalented monks. For instance if the abbey is populated mostly by talented monks there might be a strong tendency to push $k$ to a high value. In this framework, SSU and SST would remain as dynamic equilibria because they are globally stable and because SSU and SST remain as SS when $k$ decreases or increases respectively. What happens in the case in which only SSM exists is not clear. But the most challenging extension is to a general equilibrium framework. This is left for future research.

${ }^{10}$ See Sobel (2001) for a dynamic model of endogenous standards. 


\section{References}

Radner R (1991) Dynamic games in organization theory. J Econ Behav Organiz 16 (1 2): 217260

Sjostrom T, Weitzman ML (1996) Competition and the evolution of efficiency. J Econ Behav Organiz 30: 2543

Sobel J (2001) On the dynamic of standards. Rand J Econ 32 (4): 606623 